IZA DP No. 10299

Offshoring, Endogenous Skill Decision, and Labor Market Outcomes

Pablo Agnese

Jana Hromcová

October 2016 


\title{
Offshoring, Endogenous Skill Decision, and Labor Market Outcomes
}

\author{
Pablo Agnese \\ UIC Barcelona \\ and IZA \\ Jana Hromcová \\ Universitat Autònoma de Barcelona
}

Discussion Paper No. 10299

October 2016

\author{
IZA \\ P.O. Box 7240 \\ 53072 Bonn \\ Germany \\ Phone: +49-228-3894-0 \\ Fax: +49-228-3894-180 \\ E-mail: iza@iza.org
}

Any opinions expressed here are those of the author(s) and not those of IZA. Research published in this series may include views on policy, but the institute itself takes no institutional policy positions. The IZA research network is committed to the IZA Guiding Principles of Research Integrity.

The Institute for the Study of Labor (IZA) in Bonn is a local and virtual international research center and a place of communication between science, politics and business. IZA is an independent nonprofit organization supported by Deutsche Post Foundation. The center is associated with the University of Bonn and offers a stimulating research environment through its international network, workshops and conferences, data service, project support, research visits and doctoral program. IZA engages in (i) original and internationally competitive research in all fields of labor economics, (ii) development of policy concepts, and (iii) dissemination of research results and concepts to the interested public.

IZA Discussion Papers often represent preliminary work and are circulated to encourage discussion. Citation of such a paper should account for its provisional character. A revised version may be available directly from the author. 
IZA Discussion Paper No. 10299

October 2016

\section{ABSTRACT}

\section{Offshoring, Endogenous Skill Decision, and Labor Market Outcomes*}

We discuss the effects of low-skill offshoring on the endogenous schooling decision of workers along with the potential changes in the labor market. The analysis is performed in the context of a matching model with different possible equilibria. Our exercise suggests that the endogenous adjustment of low-skill workers can only partially offset the welfaredeteriorating effects of offshoring. As a result, we aim at restoring welfare by increasing the opportunity cost of staying low-skill. In addition to this, we also consider labor flexibility as an effective policy to deal with the adverse welfare effects of offshoring that befall those in the lowest end of the skill ladder.

JEL Classification: F66, I25, J64

Keywords: offshoring, welfare, skills, education, flexibility

Corresponding author:

Pablo Agnese

Economy and Business Organization Dept.

UIC Barcelona

c/ Inmaculada 22

08017 Barcelona

Spain

E-mail: pagnese@uic.es

\footnotetext{
${ }^{*}$ Financial support from the Spanish Ministry of Education and Science through grant ECO201567999-R (MINECO/FEDER) is gratefully acknowledged.
} 


\section{Introduction}

We set out to analyze the implications of the offshoring of low-skill activities on the labor market while allowing for an endogenous adjustment of educational skills. We draw on the previous literature of matching models like Albrecht and Vroman (2002), Rogerson et al. (2005), and Davidson et al. (2008), and also on our recent contribution about the potential compensating mechanisms to deal with the offshoring phenomenon (Agnese and Hromcová, 2016).

For the present paper we propose a matching model with endogenous skill requirements where employers create both high and low-skill vacancies and where the distribution of skill requirements across these vacancies is endogenous, as is the schooling decision of workers. This decision will be based on the wage differential between high and low-skill jobs. In general, low-skill workers are better off the greater the fraction of low-skill vacancies and firms with low-skill requirements are better off the greater the fraction of low-skill job candidates.

We adapt and extend the model in Albrecht and Vroman (2002) to the case of lowskill offshoring. In here, though, we interpret a lowering of low-skill productivity as a result of higher intensity in low-skill offshoring activities. Moreover, we endogenize the schooling decision of workers faced with the 'offshoring threat'. In order to come to grips with this we carry out a comparative statics and welfare analysis.

As in Albrecht and Vroman (2002) two equilibria will be discussed: the equilibrium with cross-skill matching (CSM) and the equilibrium with ex post segmentation (EPS). CSM is reached when high-skill workers and low-skill vacancies are matched, whereas EPS is what follows when these potential matches do not meet.

In order to produce a measure of low-skill offshoring we rely on an intermediate imports index as proposed by Feenstra and Hanson (1996). The rationale is that the higher the volume of intermediate trade the higher the offshoring intensity, as inputs previously produced in the home country are now being imported back from low-wage countries. To get an idea of the natural adjustment of workers to the offshoring phenomenon and to competition and globalization in general we present data for a group of highly developed countries. Figure 1 shows, with a few exceptions, a positive relationship between low-skill offshoring and the fraction of high-skill workers in the countries' populations. $^{1}$

Accordingly, our analysis below will highlight this mechanism while considering two broad skills (low and high) and also the different costs associated with the workers' educational choice. As we will see, this self-adjusting mechanism will not play

\footnotetext{
${ }^{1}$ Offshoring and education data were jointly available for a limited number of developed countries, namely: Austria, Belgium, Denmark, Finland, France, Germany, Great Britain, Italy, Japan, the Netherlands, Poland, Portugal, Spain, Sweden and the US.
} 
out completely - in other words, pre-offshoring welfare levels are not fully restored by simply endogenizing the educational decision of workers. For this reason, we aim at restoring welfare by increasing the opportunity cost of staying low-skill. This we do by introducing an incentive that lowers the cost of acquiring skills (e.g. grants or onthe-job training). We also study the effect of economic growth on the skill decision of workers and find, quite as expected, that growth unambiguously leads to a higher share of high-skill workers and a higher overall welfare level.

Figure 1: Offshoring trends and high-skill shares, 5-year averages

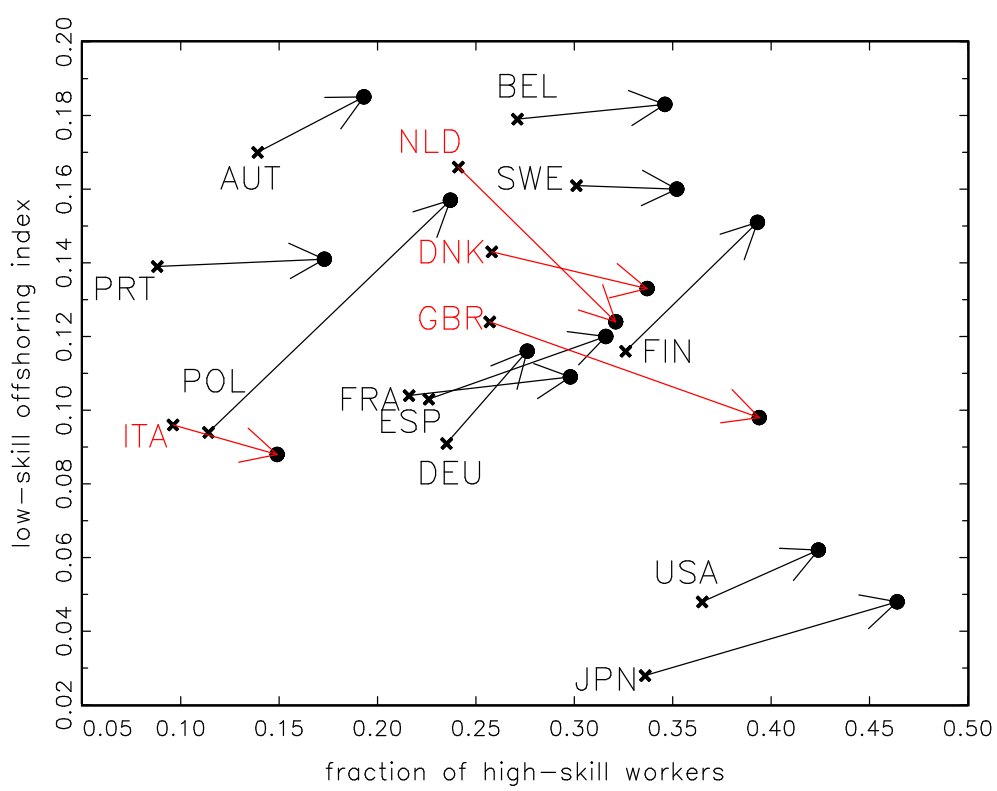

Source for offshoring index (vertical axis) is OECD Input-Output Database (2012), for skill levels (horizontal axis) is OECD Education GPS, Chapter A (2012). Note: low-skill is below secondary and post-secondary levels and high is tertiary (OECD); moreover, the data point pairs correspond to the offshoring index for mid-1990's and education level for 2000 and the offshoring index for mid-2000's and education level for 2011 .

Labor market flexibility, in turn, is suggested as the complementary policy to bring welfare back to its original level, as already discussed in earlier works (see Agnese and Hromcová, 2016, and Jung and Mercenier, 2014). In particular, we contend that it would only take a minor reduction of what we refer to as vacancy costs (e.g. firing and hiring costs) to take the economy back to previous welfare levels. In fact, allowing for a further rollback can drastically change things for the better in terms of welfare.

The remainder of the paper is organized as follows. The model, its main properties, and the possible types of equilibria are discussed in section 2. We briefly outline the strategy for the solution of the model in section 3 . The welfare effects of offshoring and the endogenous adjustment of workers in terms of education are studied in section 4 . Final remarks are summarized in section 5 . 


\section{Model}

Our model is closely related to Albrecht and Vroman (2002). Here we also consider two types of agents: workers and firms. ${ }^{2}$

Workers are infinitely lived and of measure one. They are characterized by their position in the distribution of the cost of skills acquisition, measured by the consumption goods. Each worker is indexed by $x$, his opportunity cost of remaining low-skill, raging from 0 to 1 . Workers who acquire skills will have, potentially, higher productivity levels (high-skill) than workers who do not (low-skill). The cost of acquiring skills is described by a monotonic function, $\operatorname{cost}(x)$, which satisfies

$$
\frac{d \operatorname{cost}(x)}{d x}<0 \text { and } \operatorname{cost}(1)=0
$$

The worker whose opportunity cost of remaining low-skill is the highest, the one indexed by $x=1$, becomes high-skill at zero cost, whereas the cost for the worker with $x=0$ is the largest. ${ }^{3}$

Workers are assumed to be risk neutral and thus they maximize their expected lifetime discounted net income, net wages, or net unemployment benefits (in case a worker decides to become high-skill, the cost is discounted directly from the income). Consumption is equal to the expected net income in each period, so saving is not possible. After the skill decision is taken, a fraction $q$ of workers remains low-skill, $L$, and the rest are high-skill, $H$.

There is free entry for firms and each firm employs one worker when active. A vacancy can be opened at an exogenous cost $c$-notice that $c$ includes the hiring costs, but also the firing costs that firms will potentially face in the future. Firms place vacancies of both skill types. A fraction $\phi$ of vacancies is low-skill and a fraction $1-\phi$ is high-skill and their distribution is endogenous. Firms maximize their lifetime discounted profits. Further, if a firm hires a worker to occupy a low-skill vacancy the level of output is $y_{L}$, if it hires a worker to fill a high-skill vacancy then the level of output is $y_{H}$. High-skill firms are more productive than their low-skill counterparts, thus $y_{H}>y_{L}$.

A high-skill worker is allowed to take both types of jobs, whereas a low-skill worker can only fill a vacancy that corresponds to his type. If a worker of any type is employed, he gets a wage corresponding to the type of vacancy and the type of skills he has. A

\footnotetext{
${ }^{2} \mathrm{~A}$ description of how the model works for one type of worker can be found in Rogerson et al. (2005) and Williamson (2010).

${ }^{3}$ The skill acquisition process can be compared to the so called learning-or-doing model. In the model of Lucas (1988) agents have to dedicate each period a fraction of their available time to schooling. Here they devote a fraction of their resources to schooling-training, not time, as all their available time is devoted either to working or being idle.
} 
worker of type $L(H)$ working in a job of type $L(H)$ will get a wage $w_{L}\left(w_{H}\right)$. A worker of type $H$ working in an $L$ type job will get $w_{L(H)}$. Wages earned by high-skill mismatched workers will be usually higher than wages of low-skill workers matched correctly with a low-skill job, hence $w_{H}>w_{L(H)}>w_{L}$. If a worker is unemployed he is entitled to an exogenously given unemployment benefit $b$, and any worker can refuse the job if his reservation wage is not met. Moreover, jobs are lost at an exogenous rate $\delta$.

Firms and workers meet according to a matching technology $M(u, v)$ where $u$ represents unemployed workers (unemployment rate) and $v$ vacancies. In this process an endogenously determined fraction $\gamma$ of unemployed workers will be low-skill. In addition, arrival of jobs to workers happens at a rate $\frac{M(u, v)}{u}$ and arrival of workers to employers at a rate $\frac{M(u, v)}{v}$. If we define market tightness as $\theta=\frac{v}{u}$, we can rewrite the job arrival rate to workers as $m\left(1, \frac{v}{u}\right)=m(\theta)$ and the workers' arrival rate to firms as $\frac{\frac{M(u, v)}{u}}{\frac{v}{u}}=\frac{m(\theta)}{\theta}=z(\theta)$.

If the match succeeds, the employed worker's expected lifetime utility is $W_{L}, W_{L(H)}(x)$ or $W_{H}(x)$, and the active firm's expected lifetime profits are $J_{i}, i=L, H$ or $L(H)$; where $i=L$ stands for a match between a low-skill worker and a low-technology firm, $i=H$ is a match between a high-skill worker and a high-technology firm, and $i=L(H)$ is the case where a high-skill worker matches with a low-skill firm. The utility of a worker with ability $x$ comes from earning the wage $w_{L}$ when low-skill, and the net wage $w_{H}-\operatorname{cost}(x)$ or $w_{L(H)}-\operatorname{cost}(x)$ when high-skill. All low-skill workers have the same utility, whereas the high-skill workers' utility depends on the cost of acquiring skills. The firm's profits stem from the difference between production and incurred costs, to wit, wages and search, that is $y_{i}-w_{i}-c$.

As in Okazawa (2013), the skill choice of workers depends on the comparison between its cost and the wage differential between low and high-skill workers. The worker whose cost of skill acquisition is $\operatorname{cost}(x)$ chooses to be high-skill if the wage gap is higher than the cost, i.e. ${ }^{4}$

$$
w_{H}-w_{L}>\operatorname{cost}(x),
$$

the worker on the threshold will be indifferent to remain low-skill or to become high-skill

$$
w_{H}-w_{L}=\operatorname{cost}\left(x^{*}\right)
$$

Therefore, all workers with $0<x<x^{*}$ will be low-skill and the ones with $x^{*} \geq x>1$ will become high-skill. That implies that the fraction of the labor force that remains

\footnotetext{
${ }^{4}$ In the CSM equilibrium the worker may still end up with a low-skill job, but we argue that the goal of education is to end up in a high-skill job.
} 
low-skill, $q$, will be determined by the threshold value $x^{*}$, i.e.

$$
q=x^{*}
$$

Both workers and firms take into account that the match can be broken with probability $\delta$. If the match does not succeed, an unemployed worker's expected lifetime utility is $U_{L}$ or $U_{H}(x)$, and the expected lifetime profits of a vacant firm are $V_{j}, j=L$ or $H$. In this case the low-skill worker's utility comes from earning the unemployment benefits $b$, which turn into $b-\operatorname{cost}(x)$ for high-skill workers. The firm's (negative) profits come from financing a vacancy, $-c$ (hiring and firing costs mainly). A new match between workers and firms can occur with probabilities that depend on the matching process.

We thus have that $W_{i}(x)$ stands for the value of working and $U_{j}(x)$ for the value of unemployment, while $J_{i}$ stands for the value of the job and $V_{j}$ for the value of the vacancy of the corresponding type. There is something to bargain over if the value of working is higher than the value of unemployment, $W_{H}(x)>U_{H}(x), W_{L(H)}(x)>U_{H}(x)$ and $W_{L}>U_{L}$, and when the value of the job is higher than the value of the vacancy, $J_{H}>V_{H}, J_{L(H)}>V_{L}$ and $J_{L}>V_{L}$. Wages are set to maximize the weighted surplus of workers and firms in a Nash bargaining process

$$
\max _{\left\{w_{i}\right\}}\left[W_{i}\left(w_{i}, x\right)-U_{j}(x)\right]^{\beta}\left[J_{i}\left(y_{i}-w_{i}-c\right)-V_{j}\right]^{1-\beta}
$$

where the weighting parameter $\beta$ represents the bargaining power of workers.

Utility and profit maximization problems will be characterized by Bellman equations. In what follows we describe the possible equilibria and their corresponding Bellman equations.

\subsection{Steady state equilibrium}

Workers may experience spells of employment and unemployment. When the flow of workers into and out of each employment state coincide, the steady-state equilibrium is achieved. In the steady state, low-skill workers that were working,

$$
E_{L}=q-\gamma u,
$$

and lose their jobs, equal the low-skill unemployed, $q-E_{L}$, that find a job (right hand side)

$$
\delta E_{L}=p_{L}^{W}\left(q-E_{L}\right),
$$


while high-skill workers that were working,

$$
E_{H}=1-q-(1-\gamma) u
$$

and lose their jobs, equal the high-skill unemployed, $1-q-E_{H}$, that find a job (right hand side)

$$
\delta E_{H}=p_{H}^{W}\left(1-q-E_{H}\right),
$$

where $p_{L}^{W}$ and $p_{H}^{W}$ are the probabilities to find a job for low and high-skill workers, respectively (and $\delta$ is the probability of the break of the match). ${ }^{5}$

In the described setup two types of equilibria may be realized: the equilibrium with cross skill matching (CSM) and the equilibrium with ex post segmentation (EPS). CSM occurs when high-skill workers and low-skill vacancies match, while EPS takes place when these potential matches do not meet, i.e. high-skill workers only work in high-skill jobs. The type of equilibria achieved depends on the expectations of high-skill workers about the labor market and their willingness to accept a low-skill job. Figure 2 shows the model's possible matches and payoffs.

Figure 2: Possible matches and equilibria

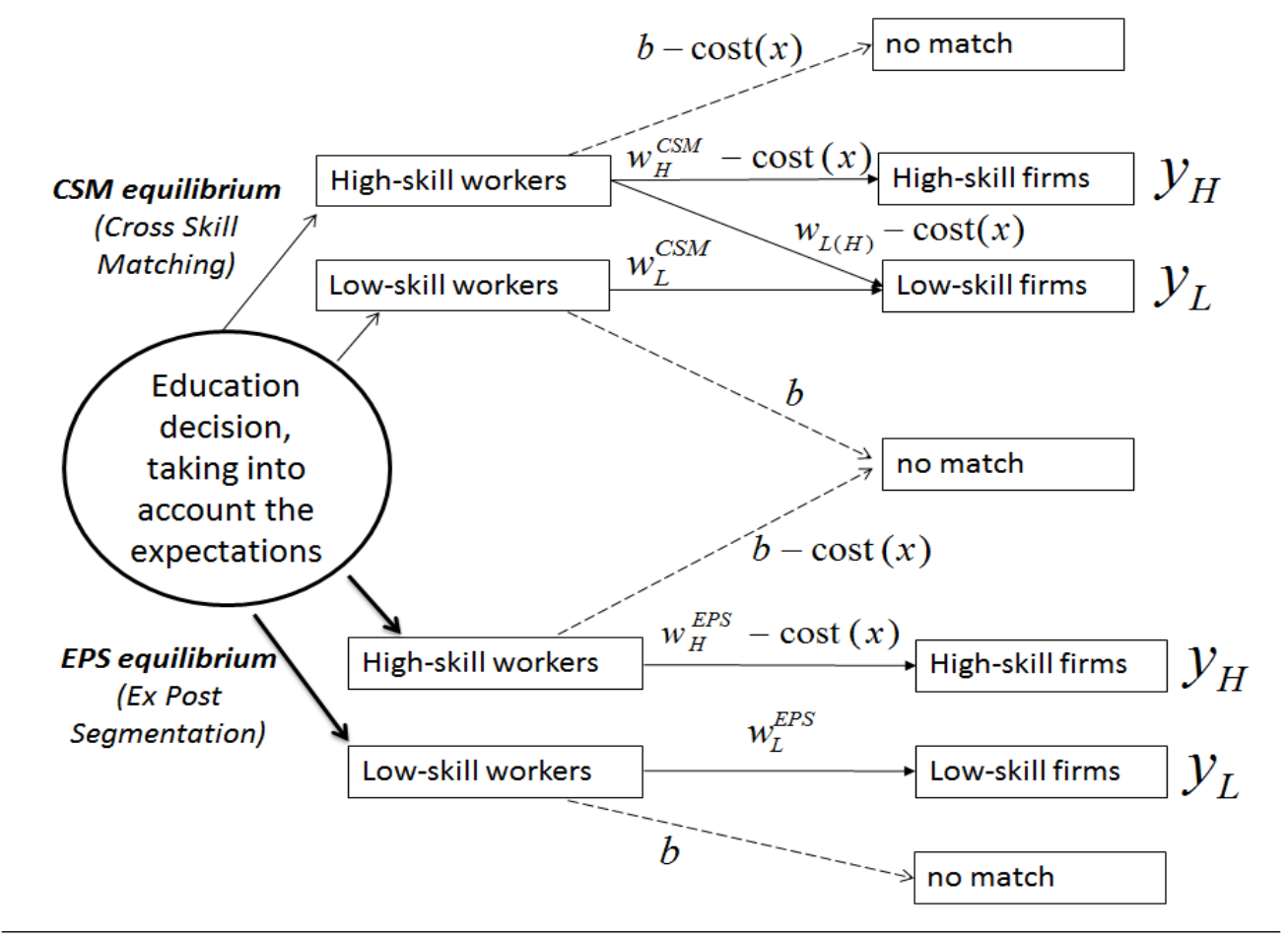

If the conditions of low-skill workers worsen because of offshoring we expect a stronger pull towards the EPS equilibrium as more individuals will choose to become

\footnotetext{
${ }^{5}$ Remember that there are $q$ low-skill workers in the labor force and $\phi$ low-skill jobs being offered. Also, a fraction $\gamma$ of unemployed is low-skill, and high-skill workers can take both types of jobs and both types of jobs meet workers at the same rate.
} 
high-skill - they will, in effect, turn down job offers and avoid the skill mismatch of the CSM equilibrium (see Agnese and Hromcová, 2016).

\subsubsection{Cross Skill Matching equilibrium}

Let us describe the equilibrium equations when high-skill workers are willing to take low-skill jobs and low-skill firms can afford to pay them.

The probability that a low-skill worker will match with a low-skill firm is

$$
p_{L}^{W}=\phi m(\theta)
$$

and the probability that a high-skill worker will match with either a low or high-skill firm is

$$
\left(p_{H}^{W}\right)^{C S M}=m(\theta) \text {. }
$$

By rewriting (6) and (8), and using (5), (7), (9) and (10), we get the expressions for the unemployment rate and the fraction of low-skill vacancies (as in Albrecht and Vroman, 2002)

$$
\begin{aligned}
u^{C S M} & =\frac{\delta(1-q)}{m(\theta)(1-\gamma)+\delta(1-\gamma)} \\
\phi^{C S M} & =\frac{(1-\gamma) q m(\theta)+\delta(q-\gamma)}{m(\theta) \gamma(1-q)} .
\end{aligned}
$$

Problem of the worker When the match between a worker and a firm is successful, the worker gets the utility which corresponds to the skill level of the firm that employs him. The following Bellman equations state that the discounted value of working (lefthand side) must be equal to the flow of net income (first item on the right hand side) and the expected loss from changing the employment status (second item on the right-hand side)

$$
\begin{aligned}
r W_{L} & =w_{L}-\delta\left(W_{L}-U_{L}\right) \\
r W_{H}(x) & =\left[w_{H}-\operatorname{cost}(x)\right]-\delta\left[W_{H}(x)-U_{H}(x)\right] \\
r W_{L(H)}(x) & =\left[w_{L(H)}-\operatorname{cost}(x)\right]-\delta\left[W_{L(H)}(x)-U_{H}(x)\right]
\end{aligned}
$$

where $r$ is the discount rate. Subscripts $L$ and $H$ characterize low and high-skill workers, respectively, matched in the corresponding firms, and $L(H)$ stands for high-skill workers mismatched in low-skill jobs. Notice that high-skill workers working for either high or low-skill firms must incur in education costs.

The analogous equations for the unsuccessful match hold: the discounted value of being unemployed must be equal to the flow of net income (net unemployment benefits) 
and the expected gain from finding a job

$$
\begin{aligned}
r U_{L} & =b+\phi m(\theta)\left(W_{L}-U_{L}\right), \\
r U_{H}(x) & =[b-\operatorname{cost}(x)]+m(\theta)\left[\phi W_{L(H)}(x)+(1-\phi) W_{H}(x)-U_{H}(x)\right] .
\end{aligned}
$$

Problem of the firm When the match is successful the Bellman equations for the active firms take the following form

$$
\begin{aligned}
r J_{L} & =\left(y_{L}-w_{L}-c\right)-\delta\left(J_{L}-V_{L}\right), \\
r J_{H} & =\left(y_{H}-w_{H}-c\right)-\delta\left(J_{H}-V_{H}\right), \\
r J_{L(H)} & =\left[y_{L}-w_{L(H)}-c\right]-\delta\left[J_{L(H)}-V_{L}\right]
\end{aligned}
$$

where the discounted value of the job must be equal to the flow of profits earned by the active firm and the expected loss from changing the labor market status (becoming inactive). The corresponding Bellman equations for the inactive firms are

$$
\begin{aligned}
r V_{L} & =-c+z(\theta)\left[\gamma J_{L}+(1-\gamma) J_{L(H)}-V_{L}\right] \\
r V_{H} & =-c+z(\theta)(1-\gamma)\left(J_{H}-V_{H}\right)
\end{aligned}
$$

where the discounted value of the vacancy must be equal to the flow of income lost by maintaining the vacancy open and the expected gain from switching to the active status. There is free entry into the market, and new firms enter while the value of the vacancy is positive. No more firms enter when the value of the vacancy decreases to zero; the free entry condition can be then expressed as

$$
V_{L}=0 \text { and } V_{H}=0 \text {. }
$$

Wage setting Wages for each type of match can be obtained by processing (13)-(15), (18)-(20), and (23), and by plugging them into (4)

$$
\begin{aligned}
w_{L} & =\beta\left(y_{L}-c\right)+(1-\beta) r U_{L}, \\
w_{H} & =\beta\left(y_{H}-c\right)+(1-\beta)\left[\operatorname{cost}(x)+r U_{H}(x)\right], \\
w_{L(H)} & =\beta\left(y_{L}-c\right)+(1-\beta)\left[\operatorname{cost}(x)+r U_{H}(x)\right] .
\end{aligned}
$$

Notice that the wage of a mismatched worker, $w_{L(H)}$, is lower than the one of a correctly matched high-skill worker, $w_{H}$, because of the former's lower productivity. Notice also that the wage of a mismatched worker, $w_{L(H)}$, is higher than the wage of a correctly matched low-skill worker, $w_{L}$ - this is so because high-skill workers have better employment options if they become unemployed, and the firm must compensate for this 
fact. ${ }^{6,7}$

The condition for the CSM equilibrium to exist is that matches between high-skill workers and low-skill jobs do take place. This happens when ${ }^{8}$

$$
y_{L}-c>\operatorname{cost}(x)+r U_{H}(x)
$$

Definition 1 In the Cross Skill Matching (CSM) steady-state equilibrium, the following must hold:

(i) workers' Bellman equations (13), (14), (15), (16) and (17),

(ii) firms' Bellman equations (18), (19), (20), (21) and (22),

(iii) Nash bargaining conditions (24), (25) and (26),

(iv) education decision condition (2),

(v) steady state conditions (6), (8), (9), and (10),

(vi) free entry conditions (23) and

(vii) CSM equilibrium condition (27). ${ }^{9}$

We evaluate separately the unemployment rates of both types of workers, the lowskill unemployment rate

$$
u_{L}=\frac{\gamma u}{q}
$$

and the high-skill unemployment rate

$$
u_{H}=\frac{(1-\gamma) u}{1-q}
$$

In the CSM steady-state equilibrium the aggregate level of output is ${ }^{10}$

${ }^{6}$ Maximizing (4), one gets the following first order condition

$$
\begin{array}{r}
\beta W_{i}^{\prime}\left(w_{i}, x\right)\left[J_{i}\left(y_{i}-w_{i}-c\right)-V_{j}\right]+(1-\beta) J_{i}^{\prime}\left(y_{i}-w_{i}-c\right)\left[W_{i}\left(w_{i}, x\right)-U_{j}(x)\right]=0, \\
i=L, L(H), H, j=L, H .
\end{array}
$$

Using (13)-(15), (18)-(20) and their derivatives, together with the free entry condition (23), we get the expressions for the corresponding wages.

${ }^{7}$ The expression $\left[\operatorname{cost}(x)+r U_{H}(x)\right]$ is constant for all $x$ and is provided in Appendix 1 , together with the expression for $r U_{L}$.

${ }^{8}$ Conditions $J_{L(H)}>V_{L}$ and $W_{L(H)}(x)>U_{H}(x)$ must hold. As $V_{L}=0$, the value of the job $J_{L(H)}$ must be positive. Whether the value of working when mismatched is greater than the value of being unempoyed can be checked by processing the corresponding Bellman equations.

${ }^{9}$ For the set of exogenous parameters $\left\{b, c, r, y_{L}, y_{H}, \beta, \delta, x ; m(\cdot), z(\cdot)\right.$, $\left.\operatorname{cost}(\cdot)\right\}$ the equlibrium conditions determine the set of endogenous values $\left\{x^{*}, q, u, v, E_{L}, E_{H}, J_{L}, J_{H}, J_{L(H)}, U_{L}, U_{H}(x), V_{L}\right.$, $\left.V_{H}, W_{L}, W_{H}(x), W_{L(H)}(x), \gamma, \theta, \phi\right\}$.

${ }^{10}$ Each worker employed in a low-skill firm produces $y_{L}$ and each worker employed in a high-skill firm produces $y_{H}$. 


$$
Y^{C S M}=E_{L} y_{L}+\phi E_{H} y_{L}+(1-\phi) E_{H} y_{H}
$$

Given that we are interested in measuring welfare, we evaluate the expected lifetime utility of the average low-skill worker (which are all alike), $\Omega_{L}^{C S M}$, and that of the average high-skill worker (which differ due to the incurred skill cost), $\overline{\Omega_{H}^{C S M}}$, as follows

$$
\begin{aligned}
\Omega_{L}^{C S M} & =\frac{E_{L} W_{L}+\left(q-E_{L}\right) U_{L}}{q}, \\
\overline{\Omega_{H}^{C S M}} & =\frac{\phi E_{H} \overline{W_{L(H)}(x)}+(1-\phi) E_{H} \overline{W_{H}(x)}+\left(1-q-E_{H}\right) \overline{U_{H}(x)}}{1-q}
\end{aligned}
$$

where variables with bars are the average values,

$$
\begin{aligned}
\overline{W_{H}(x)} & =\frac{1}{1-x^{*}} \int_{x^{*}}^{1} W_{H}(x) d x, \\
\overline{W_{L(H)}(x)} & =\frac{1}{1-x^{*}} \int_{x^{*}}^{1} W_{L(H)}(x) d x
\end{aligned}
$$

and

$$
\overline{U_{H}(x)}=\frac{1}{1-x^{*}} \int_{x^{*}}^{1} U_{H}(x) d x .
$$

The overall welfare $\Omega^{C S M}$ is the weighted sum of the two,

$$
\Omega^{C S M}=q \Omega_{L}^{C S M}+(1-q) \overline{\Omega_{H}^{C S M}}
$$

\subsubsection{Ex Post Segmentation equilibrium}

Let us now describe the equilibrium equations when high-skill workers are only matching with high-skill firms.

The probability that a low-skill worker will match with a low-skill firm does not change, so equation (9) still holds, but the probability of matching for a high-skill worker is now lower,

$$
\left(p_{H}^{W}\right)^{E P S}=(1-\phi) m(\theta)
$$

as these workers do not apply to low-skill vacancies anymore. The implied unemployment rate and the fraction of low-skill vacancies are, respectively

$$
\begin{gathered}
u^{E P S}=\frac{\delta(\gamma+q-2 \gamma q)}{\gamma(1-\gamma)[m(\theta)+2 \delta]}, \\
\phi^{E P S}=\frac{(1-\gamma) q m(\theta)+\delta(q-\gamma)}{m(\theta)(\gamma+q-2 \gamma q)} .
\end{gathered}
$$


Problem of the worker The Bellman equations that characterize the employed workers are (13) and (14), and the corresponding equations for unemployed workers are (16) and

$$
r U_{H}=[b-\operatorname{cost}(x)]+(1-\phi) m(\theta)\left(W_{H}-U_{H}\right) .
$$

Problem of the firm The Bellman equations for the active firm are (18) and (19), and for the inactive firm are

$$
r V_{L}=-c+z(\theta) \gamma\left(J_{L}-V_{L}\right)
$$

and (22). ${ }^{11}$ The zero vacancy condition (23) must also hold.

Wage setting Wages are determined by (24) and (25).

Finally, the condition for EPS equilibrium to exist is that high-skill workers are matching only with high-skill jobs

$$
y_{L}-c \leq \operatorname{cost}(x)+r U_{H}(x)
$$

Definition 2 In the Ex Post Segmentation (EPS) steady-state equilibrium, the following must hold:

(i) workers' Bellman equations (13), (14), (16) and (34),

(ii) firms' Bellman equations (18), (19), (35) and (22),

(iii) Nash bargaining conditions (24) and (25),

(iv) education decision condition (2),

(v) steady state conditions (6), (8), (9) and (31),

(vi) zero vacancy value conditions (23) and

(vii) EPS equilibrium condition (36).

Under the EPS steady-state equilibrium the aggregate level of output is

$$
Y^{E P S}=E_{L} y_{L}+E_{H} y_{H}
$$

and the welfare equations of the average low-skill and high-skill workers, $\Omega_{L}^{E P S}$ and $\overline{\Omega_{H}^{E P S}}$, are

$$
\begin{aligned}
\Omega_{L}^{E P S} & =\frac{E_{L} W_{L}+\left(q-E_{L}\right) U_{L}}{q}, \text { and } \\
\overline{\Omega_{H}^{E P S}} & =\frac{E_{H} \overline{W_{H}(x)}+\left(1-q-E_{H}\right) \overline{U_{H}(x)}}{1-q}
\end{aligned}
$$

\footnotetext{
${ }^{11}$ Notice that equations (34) and (35) now show that high-skill unemployed workers are only taking high-skill jobs, and low-skill firms are ony hiring low-skill workers.
} 
where $\overline{W_{H}(x)}$ and $\overline{U_{H}(x)}$ are defined in (28) and (30). The overall welfare $\Omega^{E P S}$ is the weighted sum of the two, as before.

\section{Solving the model}

The model can be solved numerically. In order to do so we need to specify the matching and skill acquisition functions. We assume that the matching function has a CobbDouglas form,

$$
M(u, v)=2 \sqrt{u v}
$$

which implies that the job arrival rate to workers in terms of market tightness is

$$
m(\theta)=2 \sqrt{\theta}
$$

and the workers' arrival rate to firms is

$$
z(\theta)=\frac{2}{\sqrt{\theta}} .
$$

We express the cost of acquiring skills as

$$
\operatorname{cost}(x)=\lambda(1-x)^{a}
$$

where $a \geq 1$ and $\lambda>0$. Notice that the function $\operatorname{cost}(x)$ fulfills the conditions required in section 2 -it is decreasing and the individual indexed by $x=1$ will have an infinite opportunity cost of remaining low-skill, thus he will always become high-skill. Lower values of $a$ imply a more homogeneous distribution of individuals with respect to the cost of skill acquisition, higher values indicate higher inequality. Parameter $\lambda$ measures the dispersion between the extremes of the distribution.

Using the Bellman equations for the expected lifetime utility of a vacant firm, (21) and (22) for the CSM equilibrium, and (35) and (22) for the EPS equilibrium, and the free entry condition (23), we obtain the following

$$
\begin{aligned}
\text { when } V_{L} & =0, c=z(\theta)\left[\gamma J_{L}+(1-\gamma) J_{L(H)}\right] \\
\text { when } V_{H} & =0, c=z(\theta)(1-\gamma) J_{H}
\end{aligned}
$$

for the CSM equilibrium, and

$$
\begin{aligned}
& \text { when } V_{L}=0, c=z(\theta) \gamma J_{L}, \\
& \text { when } V_{H}=0, c=z(\theta)(1-\gamma) J_{H}
\end{aligned}
$$


for the EPS equilibrium. Combining all the corresponding equilibrium equations we obtain the combinations of $\gamma$ and $\theta$, or $\gamma=f_{V_{L}=0}(\theta)$, for which (40) or (42) hold, and the combinations of $\gamma$ and $\theta$, or $\gamma=f_{V_{H}=0}(\theta)$, for which (41) or (43) hold, too. In general, for $\gamma \in(0,1), \gamma=f_{V_{L}=0}(\theta)$ is increasing and $\gamma=f_{V_{H}=0}(\theta)$ is decreasing. The intersection of the two loci determines the fraction of low-skill unemployed $\gamma$ and the market tightness $\theta$. Once these two values are known, the solution of the model can be obtained by using the corresponding equilibrium conditions. More details on the described functions can be found in Appendix 1.

\section{Comparative statics}

Offshoring can be seen as a source of skill-biased technical change. In the context of our analysis this will be modeled as a fall in the productivity level of low-skill workers. In other words, the increase of offshoring means a reduction in the value of the output produced by low-skill workers. We parametrize our model accordingly and then proceed to study the effects of offshoring.

\subsection{Parametrization}

We use the baseline parameters as in Albrecht and Vroman (2002): the rate at which the employment relationship is broken is $\delta=0.2$, meaning that jobs last on average 5 years, agents discount the future at a constant rate $r=0.05$, and the bargaining power of workers is the same as that of the firms, $\beta=0.5$. Further, the output produced by high-skill workers in a high-skill firm is assumed to be $y_{H}=1.2$. The baseline value of the output in a low-skill firm is $y_{L}=1$, a value that leads to a CSM equilibrium. The unemployment benefit amounts to about $15 \%$ of previously perceived wages, or $b=0.1$. Moreover, the cost of opening a vacancy is around $32 \%$ of total output, or $c=0.3$, and leads to an unemployment rate of $7 \%$. We take the quadratic form for the cost of acquiring skills, equation (39), by setting $a=2$; also, the value of the parameter $\lambda$ is such that in the initial (CSM) equilibrium about $2 / 3$ of the labor force remains low-skill and approximately $1 / 3$ becomes high-skill, or $\lambda=0.93$.

\subsection{The effects of offshoring}

When simulating the effects of offshoring we allow for a widening of the productivity gap between high and low-skill workers. We can see in Figure 3 the effects of an increasing productivity gap on the wage gap (vertical axis) for different skill combinations of the labor force (horizontal axis), while at the same time we compare these to the cost of 
skill acquisition (long continuous line). ${ }^{12}$

By allowing for offshoring, or what is the same in our model, by letting $y_{L}$ go down, we can see how the wage gap becomes bigger. This is depicted by a set of curves in Figure 3 with the higher indicating the bigger the productivity and wage gaps. At the same time, more people will decide to become high-skill, pushing $q$ down or to the left on the horizontal axis - notice that this also has a bearing on the wage gap, as seen by the negative slope of the curves, which are descriptive of the combinations wage gap-skill composition $(q)$. A higher payoff - or a higher wage gap in our context-will induce more workers to acquire training (see Burdett and Smith, 2002). However, it is also understood that poor matching prospects for potential high-skill workers under the CSM equilibrium can reduce the rate of return on skill acquisition. ${ }^{13}$

Figure 3: Wage gap and skill composition under CSM and EPS

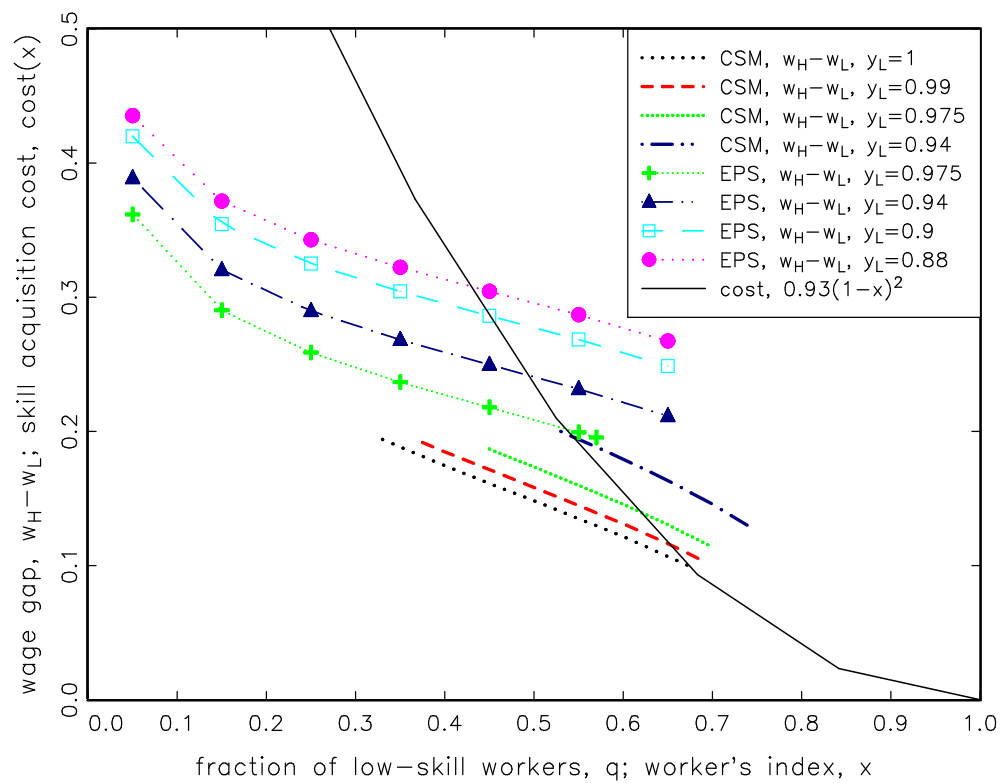

Note: Relationship between the productivity gap $\left(\mathrm{y}_{H}=1.2, \mathrm{y}_{L}\right.$ : in the legend) and the wage gap for different skill combinations $(q)$ and under different equilibria, CSM and EPS, contrasted with the cost of acquiring skills.

In our parametrization, the CSM equilibrium ceases to exist for larger productivity gaps and for higher shares of high-skill population (smaller $q$ ). As offshoring widens the wage gap, the fraction of low-skill workers will also drop and a switch from CSM to EPS will eventually take place. Both equilibria can coexist for some values of the parameters. ${ }^{14}$ The larger the productivity gap becomes the lower the share of low-skill vacancies $\phi$ that will open in the end. Table 1 summarizes our results.

\footnotetext{
${ }^{12}$ Notice that from (24)-(26) and (48)-(50) we have that lower productivity leads to lower wages.

${ }^{13}$ Note that the CSM curves in Figure 3 are low and to the right and the EPS curves are high and to the left, as the latter offers better matching prospects for those getting better skills.

${ }^{14}$ In our parametrization this happens for the productivity gap in the range of $22 \%-27 \%$.
} 


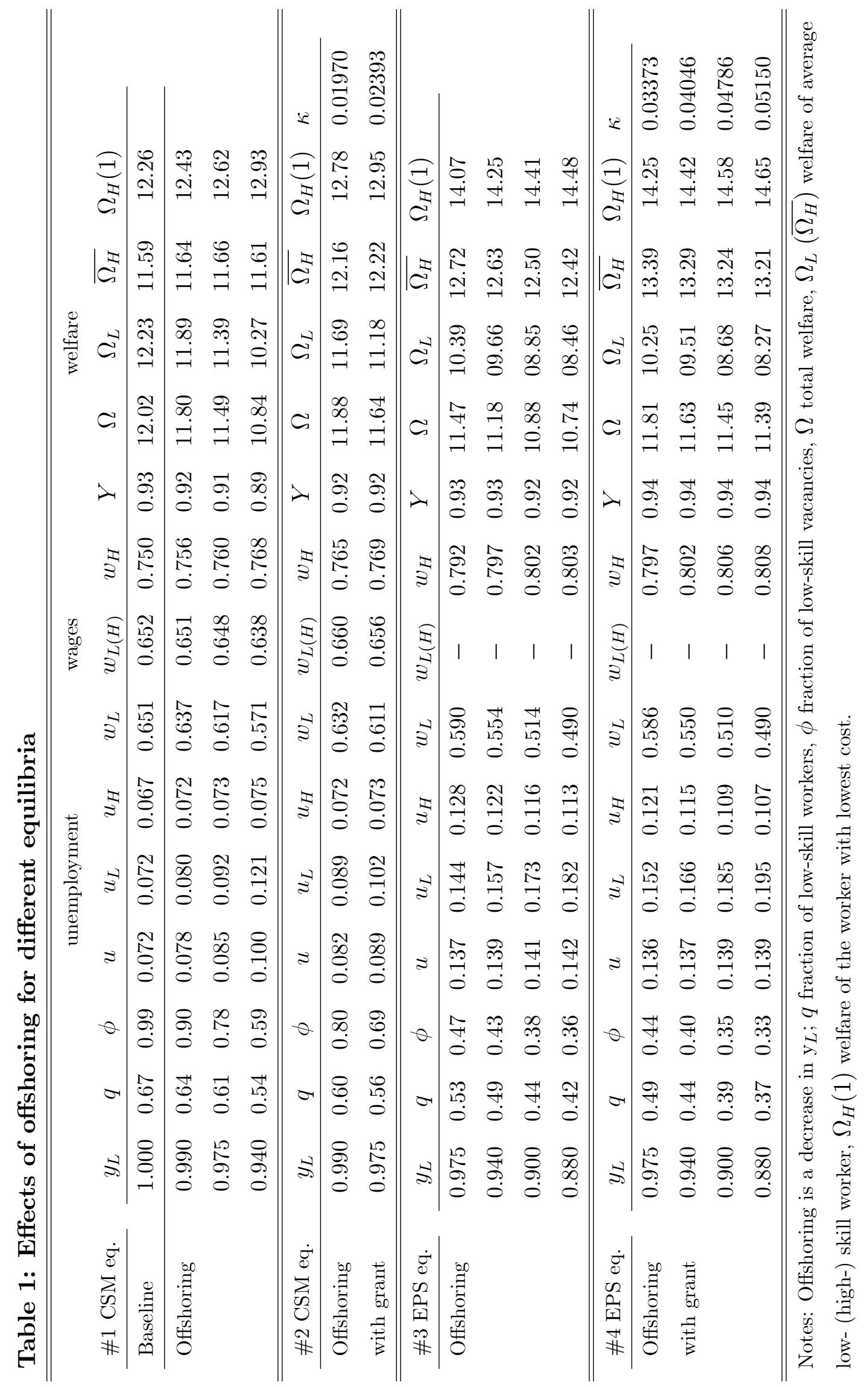


Panel \#1 in Table 1 shows, for the CSM equilibrium, the cases in which offshoring destroys about 10\%, $20 \%$ and $40 \%$ of low-skill jobs (second to fourth rows under $\phi$, respectively). Notice that this effect corresponds to the increase in the share of highskill workers (decrease in $q$ ), as high-skill wages increase and entice workers into higher productivity levels. On the other hand, the wages of low-skill workers drop more than their productivity, and the profits of low-skill firms go up (contrary to the high-skill ones) and prevent a more considerable drop of low-skill vacancies $\phi$. The unemployment rate of both types of workers increases, having a quite negative effect on the performance of the whole economy as seen by the drop in total output $Y$.

In particular, the welfare effects of offshoring are significantly negative for workers who remain low-skill, $\Omega_{L}$, and total welfare is also much decreased as the possibility of ending up in a low-skill job can make the skill-acquisition rather costly. In other words, even when some workers will choose to acquire skills and thus will become highly skilled, it does not necessarily follow that the job match will be the correct one.

Panel \#3 in Table 1 shows the offshoring effects under the EPS equilibrium-be aware that the CSM equilibrium does not exist for low values of $y_{L}$. What we observe here is that as we widen the productivity gap (e.g. offshoring) and the economy moves into the EPS equilibrium the unemployment rate makes quite a jump, both for low and high-skill workers alike. The speed at which low-skill jobs $(\phi)$ are destroyed, as the productivity gap opens further on, is now less relevant as most workers have already matched with their corresponding skills. As one would expect, low-skill wages are lower and high-skill wages are higher now than under CSM. Even when the overall unemployment rate increases sharply, a larger share of high-skill workers under EPS can now prevent the significant drop in total output as experienced under the CSM equilibrium.

Not surprisingly, the welfare effects fall heavily on low-skill workers. Moreover, the welfare of the average high-skill worker, $\overline{\Omega_{H}}$, is decreasing with offshoring, whereas the one corresponding to the best positioned high-skill individual $(x=1), \Omega_{H}(1)$, is increasing with it. However, the welfare level of high-skill workers is now remarkably higher than in the CSM equilibrium. This is due to the fact that, under EPS, highskill workers are more likely to find a high-skill job - in other words, the rewards that come with specialization and education are more likely to materialize. Total welfare is reduced as before as offshoring falls predominantly on the waning low-skill workforce.

To sum up, we conclude that for both equilibria the workers' reaction to offshoring in terms of skills acquisition (a lower $q$ ) is not enough to compensate for the initial welfare loss. In turn, the next exercise aims at showing how total welfare can be improved by helping workers through the skill acquisition process. This can be achieved, for example, by increasing the opportunity cost of staying low-skill through grants or specific on-the- 
job training. For this purpose we rewrite the skill acquisition cost function, equation (39), as

$$
\operatorname{cost}(x)=\lambda(1-x)^{a}-\kappa .
$$

Parameter $\kappa$, when positive, can be interpreted as the size of the grant or specific training program. Assuming that schooling institutions and firms can provide for this in a fixed quantity to all workers, then such mechanism could foster an increase in the fraction of workers ready to become high-skill owing to a prospective increase in the wage gap. In our example $\kappa$ is set to $50 \%$ of the average cost of acquiring skills under the corresponding offshoring shock. ${ }^{15}$

Panel \#2 (panel \#4) of Table 1 shows the results for the CSM (EPS) equilibrium with a given $\kappa$ (see last column in Table 1 ). When comparing this to our previous results in panel \#1 (panel \#3), we observe that, for both types of equilibria, changing the cost of staying low-skill through $\kappa$ causes higher unemployment for low-skill workerswhereas the one for high-skill workers remains the same (or slightly decreases). Lower costs of skill upgrading lead to a higher share of high-skill workers (a lower $q$ ) while making the economy redirect its resources towards this sector. This, eventually, results in higher wages and a higher welfare level for high-skill workers and, consequently, a higher total welfare. Such a mechanism would also bolster the EPS equilibrium - notice that, unlike in panel \#1, the CSM fails to exist for big productivity gaps (panel \#2). ${ }^{16}$

Appendix 2 shows how the model behaves for several other functional forms of the skill acquisition cost. For example, in the case of a linear cost function the cost of skill acquisition is rather high while welfare is low, but the adjustment to offshoring is very flexible and, as $q$ decreases, the economy performs efficiently with many highly productive workers. Higher non-linearity of the cost, instead, makes the adjustment to offshoring more rigid, but the skill procurement is cheap and results in better welfare outcomes.

\subsection{Offshoring, skill distribution, and growth}

In the following exercise we turn our attention to the effect of growth on the endogenous skill decision within the context of offshoring. The natural implication of growth is that a higher fraction of workers will decide to become high-skill through education or training programs as wages will eventually rise - notice that this would make for

\footnotetext{
${ }^{15}$ The size of $\kappa$ chosen modifies the initial opportunity cost of staying low-skill. When we set it to $50 \%$ of the previous average cost, we have that $\kappa=0.0197$ for the offshoring shock with $y_{L}=0.99$ in the CSM equilibrium, and $\kappa=0.0515$ for the offshoring shock with $y_{L}=0.88$ in the EPS equilibrium. See Table 1 for other possible values.

${ }^{16}$ Different policies can influence the kind of equilibrium we may expect (see the discussion in Okazawa, 2013).
} 
an increasing opportunity cost of remaining low-skill. ${ }^{17}$ This is consistent with the evidence pointing in the direction of offshoring-displaced workers being more prone to using training programs that lead to a faster reemployment pace (see Hummels et al., 2013).

Growth can set in motion a whole chain of events within a country. One unambiguous change of a growing economy is higher real wages for all, notwithstanding the increasing wage gap. Figure 4 shows the effects of offshoring and growth put together for both equilibria, CSM and EPS. The vertical axis indicates the productivity gap (e.g. offshoring) while the horizontal ones show the share of low-skill workers, $q$ (left-hand figure) and welfare, $\Omega$ (right-hand figure). Allowing for growth then, or what is the same, increasing the productivity level of both types of workers (see parameters on legends), leads to two things: first, a shift to the left of all the functions on the left-hand figure, and second, a shift to the right on the right-hand figure.

Figure 4: Effect of growth and offshoring on the skill distribution and welfare

Skill distribution

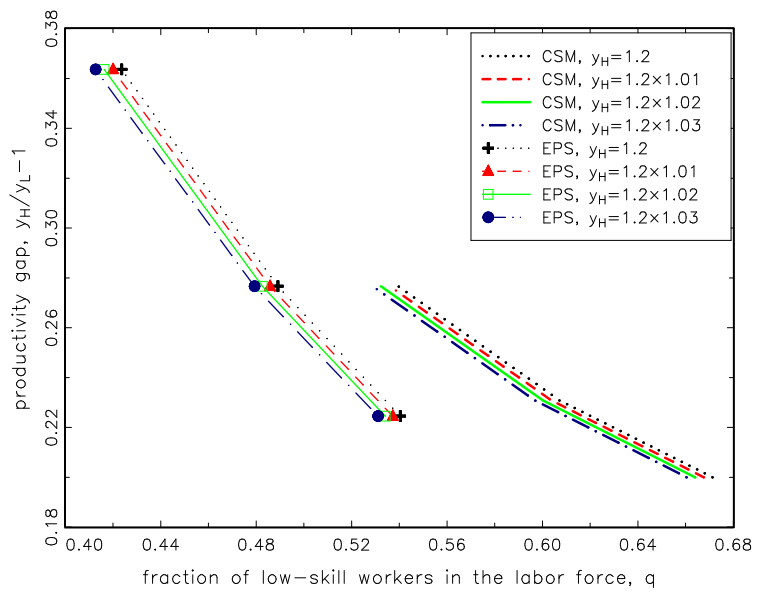

Welfare

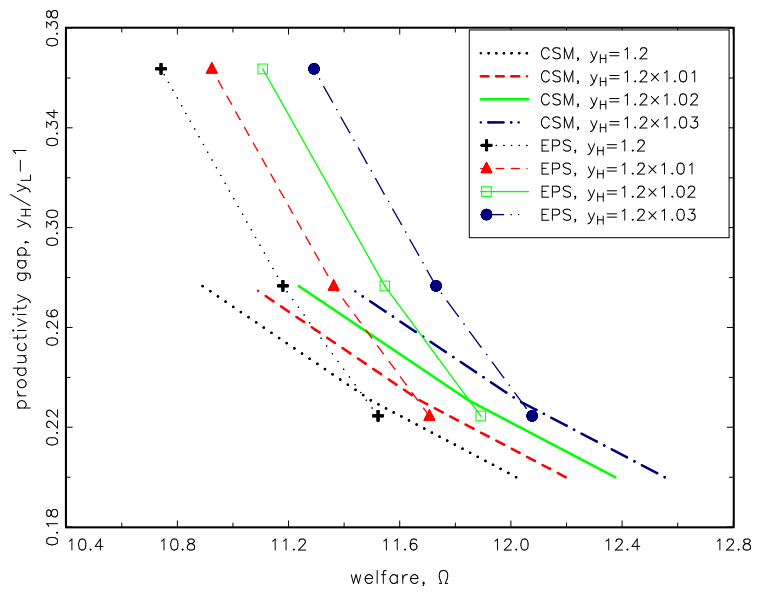

Note: Relationship between the productivity gap and the wage gap for different skill combinations $(q)$ and different welfare levels, under the two equilibria, CSM and EPS

Hence, for a given productivity gap, higher growth $(0,1,2$ and $3 \%$, as displayed on the graphs) leads to lower $q$ (or a higher share of high skill-workers) and considerably higher welfare levels $\Omega$. Notice that increasing the productivity gap (offshoring), that is, moving along the functions in both figures, causes an important increase in the fraction of high-skill workers (which experiments a jump at the point of the switch between the two equilibria) and at the same time a substantial reduction of welfare, as indicated by the slopes of these functions. We can see, however, that the welfare loss due to

\footnotetext{
${ }^{17}$ Interestingly, Blinder (2006) points out that education may not be the answer to offshoring as the critical divide in terms of what is offshorable and not does not go well with the traditional distinction between high and low-skill jobs.
} 
offshoring may be compensated by the increase in productivity that comes with the switch from CSM to EPS, where the welfare loss due to offshoring is not as important as in the CSM equilibrium. ${ }^{18}$

\subsection{Offshoring, welfare, and labor flexibility}

Welfare and inequality concerns over the offshoring phenomenon are not new to the literature, although the relation to labor markets and their resilience is less evident. ${ }^{19} \mathrm{We}$ turn now to a policy experiment that, in our view, could potentially restore the economy to pre-offshoring welfare levels. As we have shown in another place (Agnese and Hromcová, 2016), increased labor market flexibility can significantly help in achieving this result (see also Jung and Mercenier, 2014).

In the next few lines we will focus our attention on the EPS equilibrium as we expect, in general, a stronger pull in this direction. ${ }^{20}$ Let us consider a sizable productivity gap as to produce the desired EPS equilibrium, as shown in the first row of Table 2. As seen in the second row, allowing for a wider productivity gap (first column) leads to lower welfare levels (last column). However, bringing the economy's welfare back to original levels, as shown in the row labeled as $c_{\downarrow}^{\Omega}$, calls for a small reduction of $6.6 \%$ in the vacancy costs $(c)$. Notice that this will not only restore welfare $(\Omega)$ and output $(Y)$, but it will also increase low and high-skill wages $\left(w_{L}\right.$ and $\left.w_{H}\right)$, at least when compared with the offshoring row.

Table 2: Offshoring, welfare, and labor flexibility, EPS equilibrium

\begin{tabular}{|c|c|c|c|c|c|c|c|c|c|c|c|}
\hline EPS eq. & $y_{L}$ & $c$ & $q$ & $\phi$ & $u$ & $u_{L}$ & $u_{H}$ & $w_{L}$ & $w_{H}$ & $Y$ & $\Omega$ \\
\hline Baseline & 0.940 & 0.30 & 0.49 & 0.43 & 0.139 & 0.157 & 0.122 & 0.554 & 0.797 & 0.93 & 11.18 \\
\hline Offshoring & 0.880 & 0.30 & 0.42 & 0.37 & 0.142 & 0.182 & 0.113 & 0.490 & 0.803 & 0.92 & 10.74 \\
\hline \multicolumn{12}{|c|}{ Flexibility increased after offshoring } \\
\hline$c_{\downarrow}^{\Omega}$ & 0.880 & 0.28 & 0.42 & 0.37 & 0.135 & 0.172 & 0.108 & 0.515 & 0.825 & 0.93 & 11.18 \\
\hline$c_{\downarrow}^{10 \%}$ & 0.880 & 0.27 & 0.42 & 0.37 & 0.131 & 0.167 & 0.105 & 0.525 & 0.836 & 0.93 & 11.40 \\
\hline$c_{\downarrow}^{20 \%}$ & 0.880 & 0.24 & 0.42 & 0.37 & 0.120 & 0.152 & 0.097 & 0.556 & 0.869 & 0.94 & 12.09 \\
\hline
\end{tabular}

Notes: Offshoring is a decrease in $\mathrm{y}_{L}$ and flexibility stands for a reduction of the vacancy $\operatorname{costs} c$.

Notice however that if we were to allow for a more drastic drop in the vacancy expenditures, as shown in rows $c_{\downarrow}^{10 \%}$ and $c_{\downarrow}^{20 \%}$, the effects on welfare and on the low-skill

\footnotetext{
${ }^{18}$ This can be seen on the right-hand side of Figure 4 by comparing the same welfare level over different productivity gaps (moving vertically upwards for a given welfare level).

${ }^{19}$ See, among others, Ebenstein et al. (2014), Görg and Görlich (2015), Hummels et al. (2013), and the earlier contributions by Feenstra and Hanson (1996, 1997, and 1999).

${ }^{20}$ The EPS can be seen as a more efficient equilibrium where resources (e.g. labor) are used more according to their intrinsic characteristics (e.g. skills). Besides, the CSM equilibrium does not exist when the productivity gap is made sufficiently large.
} 
wage and unemployment figures will be more pronounced. For instance, with a drop in $c$ of the order of $10 \%\left(c_{\downarrow}^{10 \%}\right)$ after offshoring has taken its toll on the economy, total welfare would still be higher than in the baseline situation. Beyond that, with a $20 \%$ drop in $c$ low-skill unemployment and wages figures would still be better than originally.

Finally, a drop in the productivity of low-skill workers implies that the vacancy cost becomes relatively more expensive for low-technology firms. In numbers we have that, prior to offshoring, vacancy costs were $32 \%$ of low-skill productivity, and when $y_{L}=0.88$ the vacancy costs (still at $c=0.3$ in the second row) are $34 \%$ of low-skill productivity. By making $\frac{c^{\prime}}{y_{L}^{\prime}}\left(\frac{c^{\prime}}{Y^{\prime}}\right)$ closer to the original $\frac{c}{y_{L}}\left(\frac{c}{Y}\right)$, the labor market is made more flexible e.g. opening a vacancy is cheaper and the labor market can better serve the economy.

\section{Final remarks}

We have used a matching model to carry out a quantitative analysis of the effects of lowskill offshoring on labor market outcomes while allowing for an endogenous adjustment of skills. We have shown that offshoring has, in general, negative effects on the welfare of workers, especially low-skill ones, and that their endogenous adjustment by way of higher education cannot completely offset the welfare loss.

In the light of these results we suggest increased labor market flexibility as a way to mitigate the adverse effects of offshoring. In particular, by slightly reducing firing and hiring costs - what we referred to as vacancy costs in the text, or $c$ - it is possible to restore welfare to its pre-offshoring level. If costs are slashed even more, then the positive effects could be remarkable. Notice that these results are consistent with our previous research where the welfare-improving mechanism unleashed by increased flexibility has been proven to be very effective in a similar context (see Agnese and Hromcová, 2016).

Also, higher levels of economic growth along with higher wages will eventually help workers make the educational adjustment. For that reason it is paramount that countries, especially in the times we are in, will not depart from the traditional growth policies with a focus on work, productivity, and savings.

\section{References}

[1] Agnese, Pablo and Hromcová, Jana, 2016. Low-skill Offshoring and Welfare Compensation Policies, Economic Modelling 52, 408-426.

[2] Albrecht, James and Vroman, Susan, 2002. A Matching Model with Endogenous Skill Requirements, International Economic Review 43, 283-305. 
[3] Blinder, Alan, 2006. Offshoring: The Next Industrial Revolution?, Foreign Affairs $85,113-128$.

[4] Burdett, Ken, and Smith, Eric, 2002. The low skill trap, European Economic Review 46, 1439-1451.

[5] Davidson, Carl, Matusz, J. Steven, and Shevchenko, Andrei, 2008. Outsourcing Peter to pay Paul: High-skill Expectations and Low-skill Wages with Imperfect Labor Markets, Macroeconomic Dynamics 12, 463-479.

[6] Ebenstein, A., Harrison, A., McMillan, M. and Phillips, S., 2014. Estimating the impact of trade and offshoring on American workers using the current population surveys, Review of Economics and Statistics 96, 581-595.

[7] Feenstra, Robert C. and Hanson, Gordon H., 1996. Globalization, Outsourcing, and Wage Inequality, American Economic Review 86, 240-245.

[8] Feenstra, Robert C. and Hanson, Gordon H., 1997. Foreign Direct Investment and Wage Inequality: Evidence from Mexico's Maquiladoras, Journal of International Economics 42, 371-393.

[9] Feenstra, Robert C. and Hanson, Gordon H., 1999. The Impact of Outsourcing and High-Technology Capital on Wages: Estimates for the US, Quarterly Journal of Economics 114, 907-940.

[10] Görg, Holger and Görlich, Dennis, 2015. Offshoring, wages, and job security of temporary workers, Review of World Economics 151, 533-554

[11] Hummels, David, Munch, Jakob R., and Xiang, Chong, 2013. Education and labor market policies in an offshoring global economy, in: Nordic Economic Policy Review: Globalization, labour market institutions and wage structure, Copenhagen: Nordic Council of Ministers.

[12] Jung, Jaewon, and Mercenier, Jean, 2014. On modeling task, skill and technology upgrading effects of globalization with heterogeneous labor, Economic Modelling 39, 49-62.

[13] Lucas, Robert E., Jr., 1988. On the Mechanics of Economic Development, Journal of Monetary Economics 22, 3-42.

[14] OECD Education GPS, Chapter A, 2012.

[15] OECD Input-Output Database 2012. 
[16] Okazawa, Ryosuke, 2013. Skill-biased technical change, educational choice, and labor market polarization: the U.S. versus Europe, Journal of Economic Inequality $11,321-342$.

[17] Rogerson, Richard, Shimer, Robert and Wright, Randall, 2005. Search-Theoretic Models of the Labor Market: A Survey, Journal of Economic Literature 43, 959988.

[18] Williamson, Stephen D., 2010. Notes on Search. Washington University in St. Louis, 1-38. 


\section{Appendix}

\section{Appendix 1. Solving for Equilibrium}

Free entry conditions (40) and (41), and (42) and (43) can be rewritten using (18)-(20) and (13)-(15) as

$$
\begin{aligned}
& \text { when } V_{L}=0, c=z(\theta)\left\{\gamma \frac{(1-\beta)\left(y_{L}-c-r U_{L}\right)}{r+\delta}+\right. \\
& \left.\qquad(1-\gamma) \frac{(1-\beta)\left\{y_{L}-c-\left[\operatorname{cost}(x)+r U_{H}(x)\right]\right\}}{r+\delta}\right\}, \\
& \text { when } V_{H}=0, c=z(\theta)(1-\gamma) \frac{(1-\beta)\left\{y_{H}-c-\left[\operatorname{cost}(x)+r U_{H}(x)\right]\right\}}{r+\delta}
\end{aligned}
$$

for CSM equilibrium, and as

$$
\begin{aligned}
& \text { when } V_{L}=0, c=z(\theta) \gamma \frac{(1-\beta)\left(y_{L}-c-r U_{L}\right)}{r+\delta} \\
& \text { when } V_{H}=0, c=z(\theta)(1-\gamma) \frac{(1-\beta)\left\{y_{H}-c-\left[\operatorname{cost}(x)-r U_{H}(x)\right]\right\}}{r+\delta}
\end{aligned}
$$

for EPS equilibrium, where

$$
r U_{L}=\frac{b(r+\delta)+\beta \phi m(\theta)\left(y_{L}-c\right)}{r+\delta+\beta \phi m(\theta)}
$$

for both equilibria,

$$
\operatorname{cost}(x)+r U_{H}(x)=\frac{b(r+\delta)+\beta m(\theta)\left[\phi\left(y_{L}-c\right)+(1-\phi)\left(y_{H}-c\right)\right]}{r+\delta+\beta m(\theta)}
$$

in CSM equilibrium and

$$
\operatorname{cost}(x)+r U_{H}(x)=\frac{b(r+\delta)+\beta(1-\phi) m(\theta)\left(y_{H}-c\right)}{r+\delta+(1-\phi) \beta m(\theta)}
$$

in EPS equilibrium. These last expressions can be obtained by rewriting (16), (17) and (34) using (18)-(20), (13)-(15) and (24)-(26). The expression for $\phi$ is given by (12) and (33) for CSM and EPS, respectively. We can see that we have the system of two equations, (44) and (45) for CSM, and (46) and (47) for EPS, with two unknowns, which is nonlinear, and can deliver multiple solutions for general parameter values. However, given that parameters as $\gamma$ and $\phi$ are restricted, $0<\gamma<1,0<\phi<1$, multiple solutions are not found in our exercise. 


\section{Appendix 2. Alternative cost functions}

To study the effect of the shape of the skill acquisition cost we check the results under alternative specifications in Table A. The shapes of the cost functions under consideration are highlighted in Figure A. By increasing the grade of the polynomial in (39), that is, a higher parameter $a$, we get a highly polarized population: those workers who have a very high opportunity cost of remaining low-skill on the one hand and those who have not on the other. For instance, the linear cost function makes the economy highly reactive to offshoring, as workers are more flexible and ready to acquire new skills. Notice that for this exercise we only focus on the EPS equilibrium because it is the most likely scenario. Indeed, if individuals are made to pay a cost to become high-skill they will be less likely to accept low-skill jobs.

Notice that workers will make the decision to pursue higher levels of education based on the high-low-skill wage gap. It seems that, with the exception of the linear cost specification, and to some extent the quadratic one in our main exercise, those who are low-skill will not be easily attracted to schooling and, eventually, higher productivity and wage levels. Our view is that either the market or the current legislation are not making it possible for workers to effectively get the desired job, or else that formal education is not adequately training students for the needs of their potential employers.

Figure A: Alternative skill acquisition cost functions

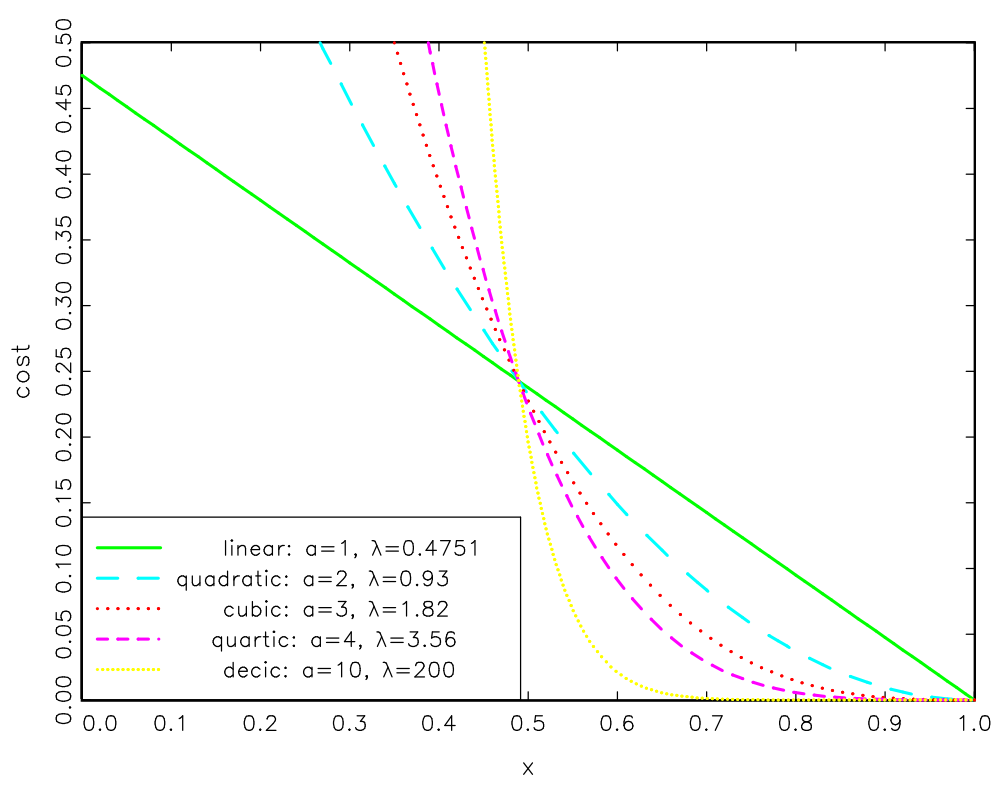

Note: Skill acquisition cost function, different specifications: linear, $\lambda(1-x)$ to 10 th degree polynomial, $\lambda(1-x)^{10}$. 


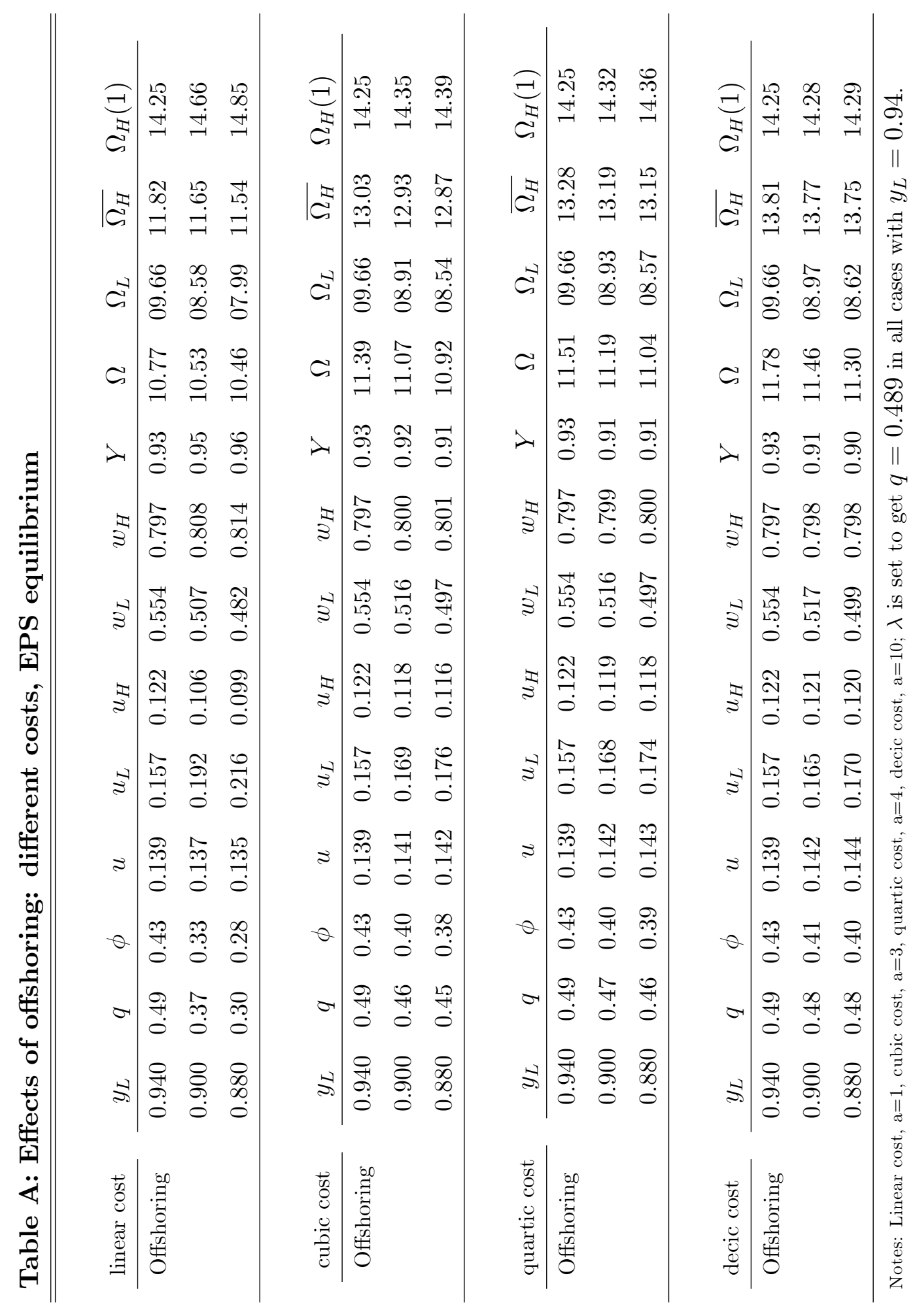

